\title{
Optimization of agrochemical application in olive groves based on positioning sensor
}

\author{
M. Pérez-Ruiz · J. Agüera · J. A. Gil • D. C. Slaughter
}

Published online: 22 October 2010

(C) The Author(s) 2010. This article is published with open access at Springerlink.com

\begin{abstract}
Typically, agrochemicals are applied to olive trees uniformly within a whole orchard without regard to the spatial variability of the target tree profile. The treatment efficiency can be improved by reducing the spray losses associated with deposition on the ground and off-target drift. The goals of this study were to develop a technique to evaluate the chemical losses resulting from a spray treatment applied to Spanish olive trees and to design an automated control system to adjust the application volume based on tree structure information incorporated in a prescription map and GPS technology. The automatic control system selectively actuated individual sections of the spray boom in real-time based upon the prescribed demand in the GPS map and the current geo-position information provided by the tractor's RTK GPS system. Test results indicated that the control system, mounted on a conventional sprayer, was able to reduce the volume of spray application on the six tree rows tested by $19 \%$ when compared to conventional spray application techniques. Results also indicated that the average application loss to the soil, for all the trees, was reduced $15.25 \%$ compared to treatment with conventional equipment. Two spray collection masts of $9.5 \mathrm{~m}$ height were designed and built to measure the drift produced during spray application and therefore to provide data for analysis of spray distribution at various application heights within the tree. Results show that the new control system was able to achieve the same spray distribution on the tree as the conventional sprayer while reducing the volume of chemical applied.
\end{abstract}

Keywords RTK-GPS - Spray deposition · Variable rate technology $\cdot$ Mapping

M. Pérez-Ruiz (ه)

Dpto. De Ingeniería Aeroespacial y Mecánica de Fluidos, Universidad de Sevilla. Área de Ingeniería Agroforestal, E.U.I.T.A. Ctra. Sevilla-Utrera Km 1, Sevilla 41013, Spain

e-mail: manuelperez@us.es

J. Agüera · J. A. Gil

Dpto. de Ingeniería Rural, Universidad de Córdoba, Córdoba, Spain

D. C. Slaughter

Department of Biological and Agricultural Engineering, University of California Davis, California, USA 


\section{Introduction}

Most agrochemical applications in Spanish orchards are currently applied using an airassisted sprayer. In Spain, orchards represent approximately $40 \%$ of the land area devoted to agricultural production (MAPYA 2007). Agrochemical applications frequently miss the target and do not produce the desired biological effect, creating an additional cost for the farmer and an increase in the environmental agrochemical load. Automated equipment capable of applying agrochemicals on a site-specific basis according to the individual needs of the vegetation at each site has proved to be a good solution to this problem (Moltó et al. 2001; Solanelles et al. 2002; Gil et al. 2007).

There are two different approaches used to implement variable-rate application technology for orchards: map-based and sensor-based. Both methods consist of four main elements: (1) sensors to detect and quantify the variables of interest (Walklate et al. 2003; Solanelles et al. 2006; Van der Zande et al. 2006; Gil and Badiola 2007; Rosell et al. 2009), (2) a data acquisition system to collect the geo-spatial data in the orchard, (3) a data processing system to produce a treatment map (García Torres et al. 2008; Ye et al. 2008), and 4) a control system that automatically adjusts the application rate using a treatment map as the input (Udompetaikul et al. 2008; Sun et al. 2010).

The most widely used sensors to detect the size of the tree and the distance between the vegetation and the machine are ultrasonic proximity sensors (Mcconnell et al. 1983; Giles et al. 1988). Giles et al. (1987) developed and tested a sprayer prototype where the sensors provided the information needed to control the spray flow based on the average vegetation volume. The sprayer was divided into three independent sub-sections each of which opened and closed in accordance with the ultrasonic sensor readings from different heights in the canopy. This technique reduced the volume of spray applied; however, reduced deposition was observed on some areas of the vegetation. Solanelles et al. (2006) developed a prototype sprayer with a control system based on ultrasonic sensors and solenoid valves designed to deliver chemical applications in proportion to the vegetation volume. Liquid savings of $70 \%, 28 \%$ and $39 \%$ in comparison to conventional applications were recorded in the olive, pear and apple orchards respectively.

The characteristics of the airflow pattern produced by the sprayer can have a large impact on the results of the spray treatment (Holownicki et al. 1996) with respect to penetration of the product into the vegetation or treatment on the underside of the leaves. An additional challenge for this type of equipment is the excessive size and irregularity of the trees in many orchards, which make equipment design difficult. For example, a field evaluation of an adjustable rate sprayer prototype in a Fuji apple tree orchard (Planas et al. 2002) showed a significant reduction in drift loss but also resulted in a less uniform distribution of the product on the vegetation, partly due to the fact that the spray tunnel was too small for the size of trees in the orchard. Nevertheless, this reduction in drift meant a $50 \%$ savings of spray materials for both apple trees and vineyards.

At present, only a small number of machines are commercially available to accomplish variable rate application of agrochemicals (Lee and Ehsani 2008). The adaptation of a normal machine for variable rate agrochemical application requires complex modifications and calibrations. Carrara et al. (2004) presented preliminary test results for the adaptation of a rate-control system to a broadcast fertilizer application system and concluded that the equipment was functional and inexpensive. Chan et al. (2004) conducted a study on the sources of error that may result from the use of nitrogen fertilizing equipment with variable-rate technology, expressing the importance of the actuator delay which modifies the rate and the horizontal precision of the GPS receiver used. 
Geo-spatial mapping of variability in orchards requires both a tree sensor and a global positioning system (GPS). For agricultural tasks like the application of pesticides and mechanical intra-row weed control, a high level of geo-position accuracy and precision is required. High-accuracy ( $\sim 10 \mathrm{~mm}$ range) geo-positioning accuracy and precision is available using real-time kinematic (RTK) GPS. Abidine et al. (2004) demonstrated the application of RTK GPS auto-guidance technology for precision inter-row cultivation operations in close proximity to buried drip-irrigation tubing $(50 \mathrm{~mm}$ target distance between the drip-irrigation tape and the cultivation zone) without damage to plants or the drip-tape. Coates et al. (2007) retro-fitted a shank type fumigant applicator with a high performance GPS (HPGPS) unit, an embedded processor, and a solenoid valve to accomplish tree-planting-site-fumigant application. Although the system appeared to work quite well, tests indicated that the RMS error in position location was $335 \mathrm{~mm}$.

Research needs to optimize agrochemical applications can be divided into three parts: better methods of generating the information needed for treatment (map-based and sensorbased), improving the performance of the treatment operation and assessment of product savings. Our initial work has focused on the development of systems to improve the performance of the treatment operation, regardless of the methodology used to obtain the information needed for orchard characterization. Variation of orchard structures in Mediterranean conditions creates a need for continued research in this area and recent technological advances in GPS technology provide an opportunity for continued development of improved sprayers.

The objectives of this study were to:

1. Develop an air-assisted spray application system that actuates spray valves and independently controls the different sprayer sections to provide improved application accuracy based on information from tree parameters and GPS technology.

2. Characterize the reduction in the application volume using this improved spray system.

\section{Materials and methods}

GPS-controlled spray system

An air-assisted sprayer (model Tornado from Delagado S.L., Córdoba, Spain) with a 10001 capacity and an axial fan, which supplied $46.5 \mathrm{~m}^{3} \mathrm{~s}^{-1}$ at an average maximum velocity of $91 / 201 \mathrm{~km} / \mathrm{h}$, was used for these tests. The spray nozzles on each side of the hydro-pneumatic sprayer were divided into three sections by height, each containing three nozzles, Fig. 1. The fluid flow in each one of these sections was controlled by an electronic solenoid-actuated valve (model Masotti, Elttromotori S.R.L., Ischitella, Italy each energized by a $12 \mathrm{~V}$ source), which allowed spray from each spray section to be controlled independently.

The geospatial location information from the centimeter-accuracy GPS system (realtime kinematic or RTK GPS quality) and the prescription map (which contained the application information for each tree) were input into a data acquisition system (DEWETRON, Graz-Grambach, Austria). A custom Visual-Basic program was developed for spray valve control. Binary (on/off) control was used for each boom section to open and close the electro-valves based on the pre-determined information about the tree being treated. 


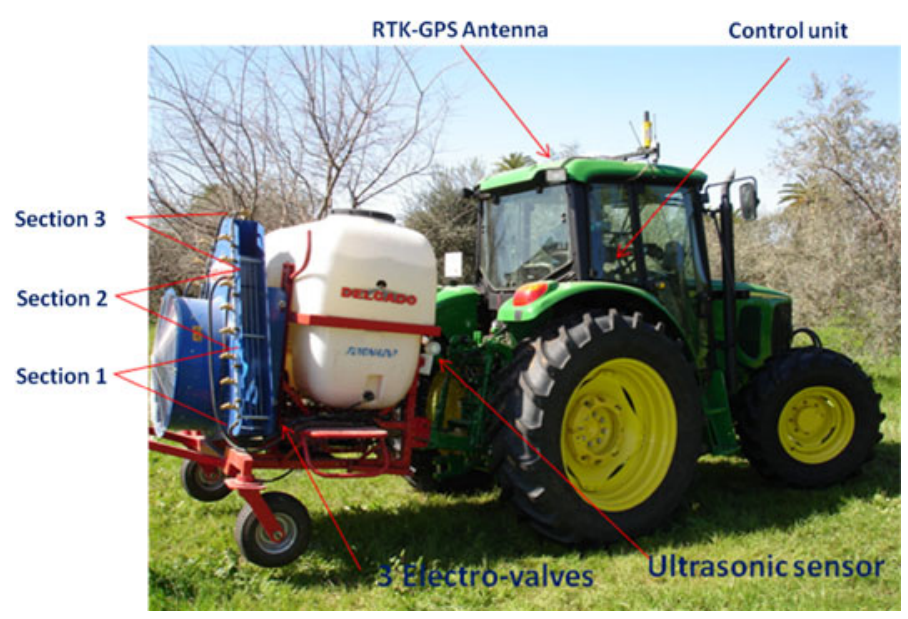

Fig. 1 Air-assisted sprayer prototype used in the field test

Method of spray characterization

A mobile spray deposition analysis system (VPE model, AAMS NV., Reningelst, Belgium) was used to characterize the spray application. Its function was to measure the distribution of the product applied by the sprayers during treatment. The equipment consisted of collection louvers, which allow the air to pass while retaining the drops of liquid applied, with a degree of separation greater than $95 \%$. The collection louvers were distributed every $100 \mathrm{~mm}$ and channeled the liquid retained towards small tubes and thence to 32 measuring test tubes. The equipment had a total height of $3.50 \mathrm{~m}$ and was set on a wheeled platform so that it could be moved in the field. It relied on gravity flow, which allowed the complete channeling of all of the liquid to test tubes for spray volume determination.

Two masts were designed and built to measure the drift produced during application. The masts were $9.5 \mathrm{~m}$ high and incorporated a pulley mechanism that allowed watersensitive papers to be positioned every $0.5 \mathrm{~m}$ for post-application analysis of the spray distribution at the application height. The mast was anchored to the ground to prevent movement when the sprayer's fan directed air over the mast. During the test these masts were strategically placed behind the treated tree.

Measurement of the flow supplied by the individual spray sections

An initial test of the system was conducted to determine the volume of water supplied by each spray section for a defined time. The water flow was collected three times for each of the divisions of the lateral section of the sprayer to ensure that the volume of water sprayed for the calculations was representative. An operating pressure of $6.10^{-5} \mathrm{~Pa}$ was used, which is a pressure similar to that used in routine treatments. Afterwards, all of the water collected was expressed measured in $1 / \mathrm{min}$ and by section to determine the output flow of the treatment equipment. This procedure was replicated five times and used to determine the application volume at the spray nozzle.

The mobile spray deposition system was used to measure the spray volume to determine the optimal opening or closing height of the solenoid-valves following calibration. For this 
test, the mobile system was placed perpendicular to the sprayer at a distance of $1.5 \mathrm{~m}$, which was the distance between the tree and the sprayer at the time of treatment.

\section{Field experiments}

Field tests were conducted during the summer of 2007. A 1.5 ha experimental olive orchard with $8 \times 8 \mathrm{~m}$ tree spacing, was selected for the study (Latitude: $37.8607389 \mathrm{~N}$, Longitude: $4.7974805 \mathrm{~W})$. The trees had only one trunk per tree and had a fairly heterogeneous canopy structure making them ideal for testing the improved sprayer.

In this test, six rows of olive trees were sprayed with the RTK-GPS air sprayer to evaluate performance based on a prescription map. The tests were performed on six olive trees located in each row, three to the left and three to the right, which were treated with the machine in each of its configurations, determining in each case and for each olive tree, the volume of liquid used and the percent area of the water-sensitive papers wetted by the liquid.

In this same experimental plot, two types of tests were designed: conventional versus improved application with the objective of analyzing the savings achieved when a conventional air sprayer is equipped with alternative technology.

Conventional application on the 36 test trees was performed at a pressure of $6.10^{-5} \mathrm{~Pa}$ and a velocity of $4.5 \mathrm{~km} / \mathrm{h}$. The spray prescription map for each of the 36 olive trees used in the GPS-based optimized application treatment was created manually using and RTKGPS surveying system. In this process, the individual tree shape was visually translated into a spray demand GPS prescription map by placing the GPS surveying pole inside the tree canopy and recording the GPS location where each spray section (1, 2 or 3 in Fig. 1) should be activated. During spray operation, the control system automatically assigned the specific binary valve coding needed to appropriately open and close the electro-valves based on the prescription map and location information provided by the RTK-GPS unit in real-time as shown in Fig. 2.

Determination of the application quantity per tree

An in situ sampling process, adaptable to all types of working conditions, was designed to evaluate the two types of applications. To compare the spray coverage and deposition on the 36 olive trees in each treatment, spray collectors (water-sensitive paper; manufactured by Syngenta Crop Protection, Inc., Greensboro, NC, USA) were used to quantify when

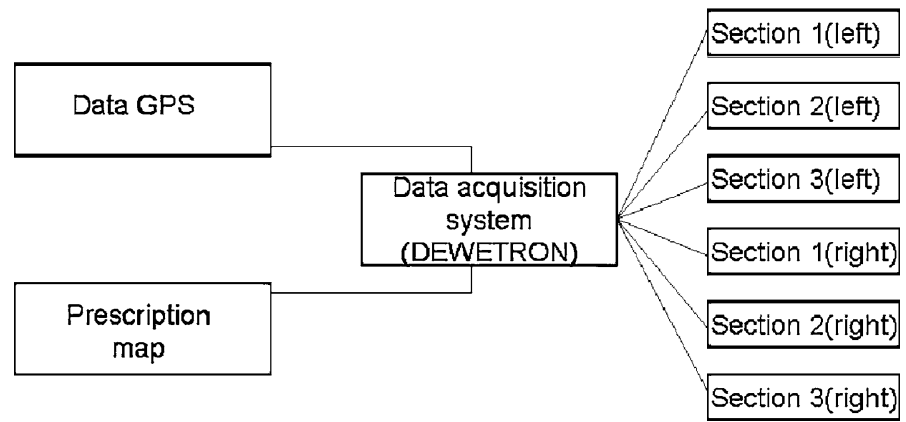

Fig. 2 Flowchart of the data processing 


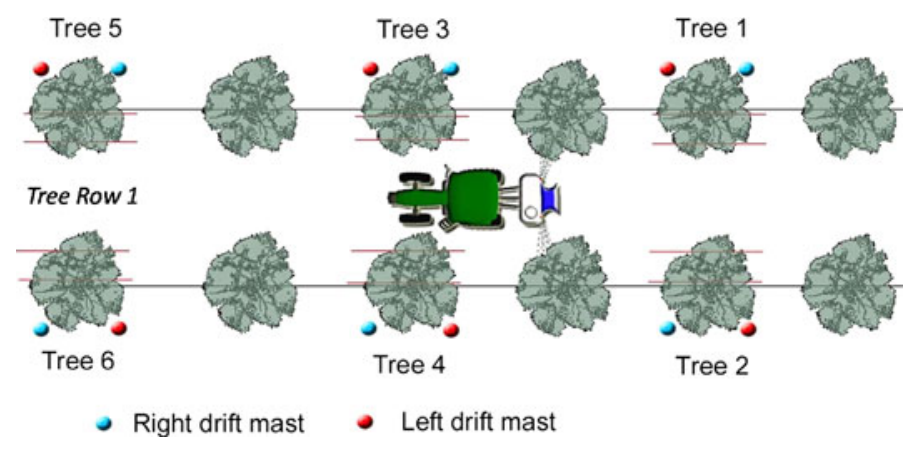

Fig. 3 System to take samples in the field test

nozzle sections were required to give proper and necessary coverage, avoid losses to soil and minimize drift. For the olive tree deposition, the spray collectors were placed (randomly distributed), in two depth planes of the tree. In pass 1, the layout of the two planes per tree can be observed for trees 1, 3, 5, 2, 4 and 6 in Fig. 3. The first plane in the area close to the center of the row and the second plane practically in the center of the tree. In addition, the previously described masts were used to measure the drift. In each one of the planes, eleven $26.5 \mathrm{~mm}$ by $78 \mathrm{~mm}$, water-sensitive paper cards were randomly distributed to cover the greatest sampling area. The masts were situated just behind the trees to measure the drift produced in both treatments and to verify whether or not there was a reduction in drift with the optimized application. After drying, the spray cards were collected and given an identification number for subsequent assessment using image analysis.

The water-sensitive papers collected from the trees, soil and masts were scanned with a Photo Scanner (Epson Perfection 1200U) at 600 dpi and control parameters were given so that all of the images had the same quality (Exposure: 0; Gamma: 244; Luminosity: 248; Shade: 37). Subsequently, the images were imported to Matrox Inspector 4.0 software (Matrox Imaging, Inc., Quebec, Canada), and converted into a binary format and using a gray threshold selected to minimize the effect of size distortion. The total number of drops deposited was calculated by the software for each image.

With the purpose of evaluating conventional and improved applications, some simple hydraulic and kinematic calculations were performed to determine the quantity of liquid applied per tree in both treatments.

In a first step, the distance $\left(L_{\mathrm{t}}\right)$, measured on the axis parallel to the application direction, was collected for all of the trees (Fig. 4). Afterwards, the time (s) taken by the sprayer to pass in front of each olive tree was calculated using the velocity of the vehicle during the treatment $(4.5 \mathrm{~km} / \mathrm{h})$.

For the conventional application, where all of the divisions on the nozzle sections were held open, the quantity in liters supplied to each tree was calculated from $L_{\mathrm{t}}$, the time (s) and with the knowledge that the average flow $\left(1 \mathrm{~s}^{-1}\right)$ provided by each of the divisions made on the nozzle section of the sprayer as shown in Eq. 1:

$$
C_{t}=Q \times t
$$

where $C_{\mathrm{t}}$ is the total volume per tree (1), $Q$ is the applied flow rate $\left(1 \mathrm{~s}^{-1}\right)$ and $t$ is the application time (s).

The calculation of the quantity applied to each tree for the improved sprayer was performed in the same way. 


\section{Conventional Spray Application \\ Length of the tree: $L_{t}=5.500 \mathrm{~m}$ \\ Applied time: $T_{t}=4.440 \mathrm{~S}$ \\ Applied flow: $Q_{1}=12.193 \mathrm{~V} / \mathrm{min}$ \\ Volume: $\mathrm{C}_{\mathrm{t}}=0.9021$ \\ GPS Optimized Spray Application}

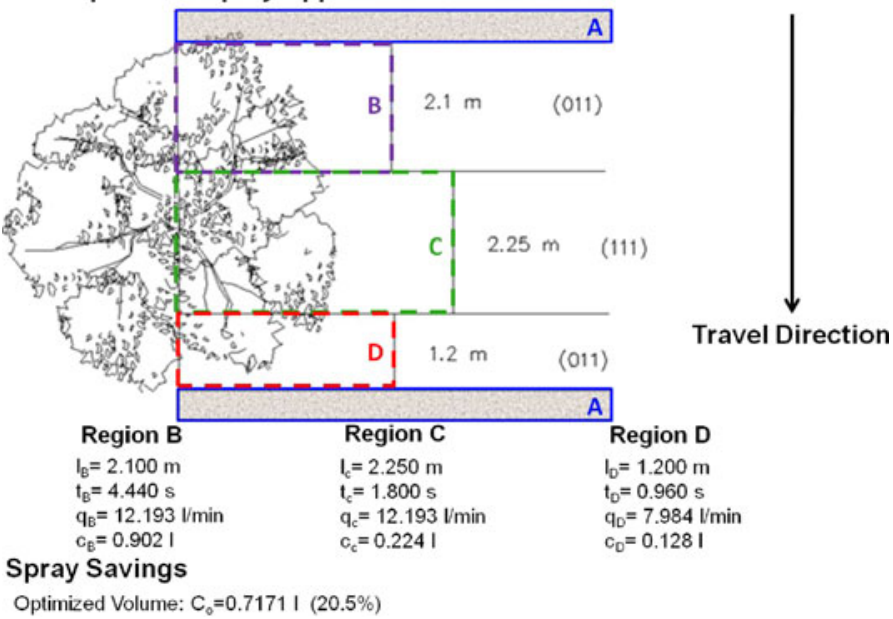

Fig. 4 Illustration showing the calculation of conventional and optimized volume application and the four application zones for tree 1: $A=$ intra-row tree (blue with gray points), $B=$ from start application until the first structural variation zone (purple dashes), $C=$ central part of the tree mass zone (green dashes), and $D=$ from the last structural variation to the end of the tree mass zone (red dashes). (Color figure online)

The performance of the improved air-assisted sprayer was evaluated by calculating the difference in the quantity of liquid applied between the conventional, and improved system. The mean and standard deviation (SD) percentage of saving were calculated for each tree row in the test and the SAS general linear models procedure (SAS Institute Inc. 2008) was used to test for significant differences in applied spray between systems using ANOVA.

\section{Results and discussion}

An automatic air-assisted sprayer, which utilized a GPS prescription tree map to determine the geospatial position to open and close the spray-valves in the field, was successfully developed and operated in a processing olive orchard in Spain. The system was specifically designed to optimize the spray application according to the characteristics of the canopy target, in accordance with other research projects (Gil et al. 2007; Llorens et al. 2010).

\section{Laboratory tests}

The laboratory test compared the flow rate collected by the silicone tubes attached to each nozzle with the flow rate collected by the mobile deposition collection system. The difference between the flow rate values by valve section provides the value for the flow rate lost over the distance traveled by the liquid from the time it leaves the nozzle until it reaches its target. The losses of the sections on the right and left sides are represented by 
Table 1 Difference between the applied flow rate and collected flow rate

\begin{tabular}{|c|c|c|c|c|c|c|}
\hline & \multicolumn{3}{|l|}{ Right side } & \multicolumn{3}{|l|}{ Left side } \\
\hline & Section 1 & Section 2 & Section 3 & Section 1 & Section 2 & Section 3 \\
\hline Applied flow rate $\left(1 \mathrm{~min}^{-1}\right)$ & 3.82 & 4.16 & 4.21 & 4.40 & 4.59 & 4.26 \\
\hline Collected flow rate $\left(1 \mathrm{~min}^{-1}\right)$ & 2.93 & 2.47 & 0.91 & 3.21 & 3.13 & 0.91 \\
\hline Difference flow rate $\left(1 \mathrm{~min}^{-1}\right)$ & 0.90 & 1.69 & 3.30 & 1.18 & 2.46 & 3.35 \\
\hline Losses $(\%)$ & 23.42 & 40.62 & 78.30 & 26.93 & 43.97 & 78.60 \\
\hline
\end{tabular}

the average values shown in Table 1 . These results show that the applied flow rate in the two sides of the air-assisted sprayer prototype were different, with the left side higher by $4 \%$ compared to the right as an average value for a power take-off (p.t.o.) rotational speed of 540 RPM. The difference between both sides was similar in magnitude to that observed by Herrera et al. (2005), and indicated that the fan and baffles were working properly. The movement of the air generated by the fans plays a vital role in improving the transport and deposition of droplets of plant protection products onto the canopy (Ganzelmeier et al. 1995; Racke 2003). Furthermore, inadequate design of the fan may have serious repercussions on the amount of drift and production costs (Delete et al. 2005). The values presented in Table 1 show that the approximate flow rate loss was 131 of liquid per minute under normal working conditions. This test was very useful for measuring the losses that occurred during a laboratory application, where conditions such as air velocity and room temperature could be easily controlled. It is worth mentioning that the greatest losses were produced in the third valve section (top section), with losses close to $80 \%$ of the flow rate administered. This section required the drops of water to travel the longest distance in order to reach the target. The off-target loss (ground deposit plus spray drift) was similar in magnitude to that observed by Holownicki et al. 2000).

Field tests

The air-assisted sprayer prototype was pulled behind a tractor steered by an RTK GPS autoguidance system. All field tests were conducted with a tractor steered by GPS autoguidance using a common set of GPS AB line coordinates for all the olive trees rows and an accuracy within $30 \mathrm{~mm}$ of the desired $\mathrm{AB}$ line was obtained. These results are superior to those of Balsari et al. (2008) under similar conditions in a field test where the accuracy was less than $100 \mathrm{~mm}$. The mounting location of the RTK-GPS antenna on the tractor allowed good satellite geometry to be obtained during the experiment and RTK GPS fixed quality was obtained for all antenna positions recorded during the prescription map event and variable application.

Using the results obtained with the mobile deposition collection system, the height reached and the area sprayed were determined for each of the spray sections. Tree height and shape was used to independently control the actuation of the different nozzle sections of the prototype: section 1 (bottom) $<1.8 \mathrm{~m}$, section 2 (middle) $1.8-2.9 \mathrm{~m}$, and section 3 (top) $>2.9 \mathrm{~m}$. The measured flow rate in Table 1 shows a close agreement between the two sides of the sprayer and is characterized by a lower liquid volume deposited on the mobile collection system at heights above $2.9 \mathrm{~m}$ and similar liquid volume collected at the heights between 0 and $2.9 \mathrm{~m}$. 
Table 2 Percent spray savings (conventional/optimized) in different tree rows

\begin{tabular}{|c|c|c|c|c|c|c|}
\hline \multirow[b]{2}{*}{ Tree Row } & \multirow[b]{2}{*}{ Trees } & \multicolumn{2}{|c|}{ Conventional volume $\mathrm{Ct}$ (1) } & \multicolumn{2}{|c|}{ Optimized volume Co (1) } & \multirow{2}{*}{$\begin{array}{l}\text { Percentage (\%) saved } \\
\text { Mean }\end{array}$} \\
\hline & & Mean & S.D. & Mean & S.D. & \\
\hline 1 & 6 & 0.90 & 0.15 & 0.72 & 0.14 & 20.00 \\
\hline 2 & 6 & 0.75 & 0.20 & 0.63 & 0.18 & 16.00 \\
\hline 3 & 6 & 1.06 & 0.19 & 0.76 & 0.19 & 28.30 \\
\hline 4 & 6 & 0.88 & 0.12 & 0.75 & 0.14 & 14.77 \\
\hline 5 & 6 & 1.41 & 0.13 & 1.18 & 0.16 & 16.31 \\
\hline 6 & 6 & 1.42 & 0.14 & 1.09 & 0.19 & 23.24 \\
\hline Total* & 36 & $1.07^{\mathrm{a}}$ & 0.16 & $0.86^{\mathrm{b}}$ & 0.17 & 19.77 \\
\hline
\end{tabular}

* Total mean spray volumes delivered by the conventional and optimized spray systems were significantly different at $\alpha=0.01$

Consistent with the general objective of designing, building and evaluating the improvements made to conventional machines to optimize their performance using GPS technology, the comparative analysis of the results obtained from the different tests shows important differences between treatments with a conventional sprayer versus the improved GPS air-assisted sprayer (Table 2).

Figure 4 illustrates an example showing the calculation of conventional (top of Fig. 4) and optimized (bottom of Fig. 4) application volumes for the four different situations that resulted in different application events for the example olive tree. Region A is the intraolive tree zone (all valve sections are closed here). Region B extends from the beginning of the vegetation to the first structural variation zone (here valve sections 1 and 2 are open and section 3 is closed). Region $\mathrm{C}$ is the central part of the tree mass zone (here all valve sections are open). Region $\mathrm{D}$ extends from the last structural variation to the end of the tree mass zone (here valve sections 1 and 2 are open and section 3 is closed).

The results of the field test, where the air-assisted sprayer prototype was operated in six trees rows (on 36 olive trees), are shown in Table 2. For all of the trees tested, there was a decrease in the amount of spray mixture applied using the improved system. In addition, there was a reduction of drift for these same trees, with no large variations in the distribution of the spray mixture on the olive trees between treatments using the conventional equipment versus the improved system.

The data in Table 2 shows the mean and standard deviation values for the total saving in the applied liquid for the six tree rows. Comparison of these results shows that, in all cases, the savings produced during application using the improved air sprayer were greater than $14 \%$. The magnitude of the savings was lower than those observed in other research projects. The higher level of structural variations present in the traditional Spanish olive trees in comparison with vineyard (Gil et al. 2007), citrus (Salyani et al. 2007) and apple trees (Cross et al. 2001) structures may account for this difference.

With respect to the spray applied to the soil, the results clearly show how, in general, for all of the trees, treatment using conventional equipment generates more losses on the soil under the tree than with treatment using the improved system. The data in Table 3 shows the mean and standard deviation values for percent spray losses due to application on the ground located under the trees.

In addition to spray savings, it is important to assess if all the reduced spray volume has any effect on the distribution of the deposited spray. By maintaining the same deposition and biological efficacy in both applications, conventional and optimized, good control of 
Table 3 Percent spray losses due to application on the ground located under the tree

\begin{tabular}{|c|c|c|c|c|c|}
\hline \multirow[b]{2}{*}{ Tree row } & \multirow[b]{2}{*}{ Trees } & \multicolumn{2}{|c|}{ Conventional application } & \multicolumn{2}{|c|}{ Optimized application } \\
\hline & & Mean & S.D. & Mean & S.D. \\
\hline 1 & 6 & 8.44 & 1.75 & 7.80 & 1.15 \\
\hline 2 & 6 & 12.06 & 2.42 & 10.80 & 1.75 \\
\hline 3 & 6 & 14.85 & 3.03 & 14.90 & 2.95 \\
\hline 4 & 6 & 12.00 & 2.20 & 8.50 & 2.10 \\
\hline 5 & 6 & 11.30 & 1.90 & 9.20 & 1.50 \\
\hline 6 & 6 & 17.26 & 2.94 & 13.90 & 3.40 \\
\hline Total* & 36 & $12.65^{\mathrm{a}}$ & $2.37^{\mathrm{b}}$ & 10.85 & 2.14 \\
\hline
\end{tabular}

* Total mean spray volumes applied to the ground by the conventional and optimized spray systems were significantly different at $\alpha=0.01$

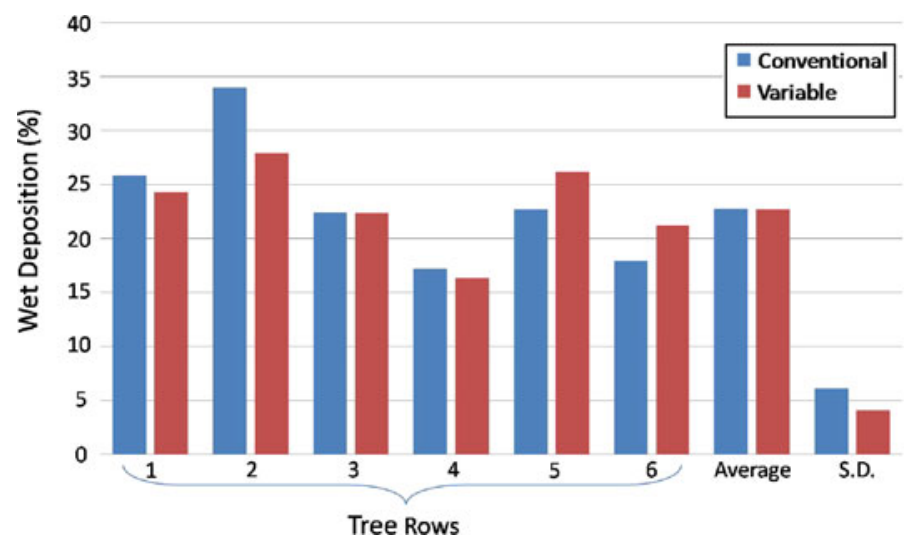

Fig. 5 Wet depositions (\%) in the tree canopy obtained by conventional application (blue) and with the optimized application system ( $r e d$ ). (Color figure online)

the pest (Chueca et al. 2009) is ensured. The spatial distributions of deposits on the watersensitive cards in the whole canopy are shown in Fig. 5. In general, high uniformity can be observed in all trees, independent of the spray method (conventional or optimized). With regard to the spray coverage achieved on the tree, Fig. 5 indicates that there were no significant differences, indicating that the same effect was achieved on the tree row even when less spray quantity was applied.

The placement of drift masts in the row adjacent to the treated trees and directly behind the tree to be treated, together with the subsequent analysis of the water-sensitive papers, revealed that the drift was practically the same for treatment with the conventional equipment and treatment with the improved equipment (unpublished data).

\section{Conclusion}

An automatic air-assisted sprayer, which utilized a GPS-based prescription tree map to determine the geospatial position at which the spray-valves were opened and closed in the 
field, was successfully develop and operated in a production olive orchard in Spain. The system utilized RTK GPS location, prescription maps and a data acquisition unit, interfaced to an air-assisted sprayer to produce a variable-rate spray applications optimized to match the structural variations of the vegetation. The following conclusions were drawn based upon the results of this research:

- A technique was successfully developed by combining water-sensitive paper and image analysis, which allowed for quick and economic measurement of the quality of a spray treatment with regards to the area of the tree covered and the product losses resulting from treatment.

- The system could be used in precision agriculture for implementing the site-specific management techniques for the variable-rate application of tree production inputs, using a map-based prescription.

- The improved hydro-pneumatic sprayer with GPS technology used in this work provided an application volume adapted to the characteristics of the tree, without reducing the quality of the treatment, while providing a savings of about $20 \%$ in applied spray volume. These savings in applied chemicals will not only reduce the cost but also reduce the environmental impact caused by these chemicals.

Acknowledgments The financial support received from the Spanish Ministry of Science and Technology (Project: INIA N ${ }^{\circ}$ RTA 2006-00058-C03-03) and The Regional Government of Andalucía (Project: CAO01-022) is greatly appreciated.

Open Access This article is distributed under the terms of the Creative Commons Attribution Noncommercial License which permits any noncommercial use, distribution, and reproduction in any medium, provided the original author(s) and source are credited.

\section{References}

Abidine, A. Z., Heidman, B. C., Upadhyaya, S. K., \& Hills, D. J. (2004). Autoguidance system operated at high speed causes almost no tomato damage. California Agriculture, 58(1), 44-47.

Balsari, P., Doruchowski, G., Marucco, P., Tamagnone, M., Van de Zande, J., \& Wenneker, M. (2008). A system for adjusting the spray application to the target characteristics. Agricultural Engineering International: the CIGR Ejournal, pp. 1-12. Manuscript ALNARP 08002 Vol. X.

Carrara, M., Comaretti, A., Febo, P., \& Orlando, S. (2004). Spatially variable rate herbicides application on durum wheat in Sicily. Biosystems Engineering, 87, 387-392.

Chan, C. W., Schueller, J. K., Miller, W. M., Whitney, J. D., \& Cornell, J. A. (2004). Error sources affecting variable rate application of nitrogen fertilizer. Precision Agriculture, 5, 601-616.

Chueca, P., Garcerá, C., Pina, T., Urbaneja, A., Jacas, J., \& Moltó, E. (2009). Optimization of water volume used in mineral oil application to control Tetranichus urticae in citrus. SuproFruit 2009, $10^{\text {th }}$ Workshop on Spray Application Techniques in Fruit Growing (pp. 76-78). The Netherlands: Wageningen UR, Plant Sciences Group.

Coates, R. W., Shafii, M.S., Upadhyaya, S. K., \& Browne, G. T. (2007). Site-specific fumigant applicator for prevention of almond replant disease. ASABE Paper No. 071080. ASABE, St. Joseph, MI 49085, USA.

Cross, J. V., Walklate, P. J., Murray, R. A., \& Richardson, G. M. (2001). Spray deposits and losses in different sized apple trees from an axial fan orchard sprayer: 1. Effects of spray liquid flow rate. Crop Protection, 20, 13-30.

Delete, M. A., De Moor, A., Sonck, B., Ramon, H., Nicolai, B. M., \& Berboven, P. (2005). Modelling and validation of the air flow generated by a cross flow air sprayer as affected by travel speed and fan speed. Biosystems Engineering, 92(2), 165-174.

Ganzelmeier, H., Rautmann, D., Spangenberg, R., Strekole, M., Herrmann, M., \& Wenzelburger, H. J. (1995). Studies on the spray drift of plant protection products. Berlin, Germany: Blackwell Wissenschafts-Verlag GmbH. 
García Torres, L., Peña-Barragán, J. M., López-Granados, F., Jurado-Expósito, M., \& Fernández-Escobar, R. (2008). Automatic assessment of agro-environmental indicators from remotely sensed images of tree orchards and its evaluation using olive plantations. Computers and Electronics in Agriculture, 61, 179-191.

Gil, E., \& Badiola, J. (2007). Design and verification of a portable vertical patternator for vineyard sprayer calibration. Applied Engineering in Agriculture, 23(1), 35-42.

Gil, E., Escola, A., Rosell, J. R., Planas, S., \& Val, L. (2007). Variable rate application of plant protection products in vineyard using ultrasonic sensors. Crop Protection, 26, 1287-1297.

Giles, D. K., Delwicke, M. J., \& Dodd, R. B. (1987). Control of orchard spraying based on electronic sensing of target characteristics. Transactions of the ASABE, 30(6), 1624-1630.

Giles, D. K., Delwiche, M. J., \& Dodd, R. B. (1988). Electronic measurement of tree canopy volume. Transactions of the ASABE, 31(1), 264-272.

Herrera, M. I., Martins, M., Rodrigues, G. J., \& Cuevas-Millán, H. (2005). Aerodinámica del ventilador axial del pulverizador HATSUTA-420 empleado en frutales [Aerodynamics of the axial fan of the HATSUTA-420 sprayer employed in orchards]. Revista Ciencias Técnicas Agropecuarias, 14(3), 23-30.

Holownicki, R., Doruchowski, G., \& Swiechowschi, W. (1996). Uniformity of spray deposit within apple tree canopy as affected by direction of the air-jet in tunnel sprayers. Journal of Fruit and Ornamental Plant Research, 3, 129-136.

Holownicki, R., Doruchowski, G., Godyn, A., \& Swiechowski, W. (2000). Effects of air jet adjustment on spray losses in orchard. Aspects of Applied Biology, 57, 293-300.

Lee, K., \& Ehsani, R. (2008). Comparison of two 2D laser scanners for sensing object distances, shapes, and surface patterns. Computers and Electronics in Agriculture, 60(2), 250-262.

Llorens, J., Gil, E., Llop, J., \& Escola, A. (2010). Variable rate dosing in precision viticulture: Use of electronic devices to improve application efficiency. Crop Protection, 29(3), 239-248.

MAPYA. 2007. Analysis of tree orchards plantations, Technical General Secretariat, Spanish Ministry of Agricultural, Fisheries and Food, Madrid, Spain, 17 pp. http://www.mapa.es/en/estadistica/pags/ anuario/2007/indice.asp (in Spanish). Accessed 02 Aug 2010.

Mcconnell, R. L., Elliot, K. C., Blizzard, S. H., \& Koster, K. H. (1983). Electronic measurement of tree row volume. Agricultural Electronics, 1, 85-90.

Moltó, E., Martin, B., \& Gutiérrez, A. (2001). Pesticide loss reduction by automatic adaptation of spraying on globular trees. Journal of Agricultural Engineering Research, 78(1), 35-41.

Planas, S., Solanelles, F., \& Fillat, A. (2002). Assessment of recycling tunnel sprayers in Mediterranean vineyards and apple orchards. Biosystems Engineering, 82(1), 45-52.

Racke, K. D. (2003). Release of pesticides into the environment and initial concentrations in soil, water, and plants. Pure and Applied Chemistry, 75(11-12), 1905-1916.

Rosell, J. R., Sanz, R., Llorens, J., Arnó, J., Escolá, A., Ribes-Dasi, M., et al. (2009). A tractor-mounted scanning LIDAR for the non-destructive measurement of vegetative volume and surface area of treerow plantations: A comparison with conventional destructive measurements. Biosystems Engineering, $102,128-134$.

Salyani, M., Muhammad, F., \& Sweeb R. D. (2007). Mass balance of citrus spray applications. Paper No 071037. ASABE, St. Joseph, MI 49085, USA.

SAS Institute Inc. (2008). SAS/STAT 9.2 user's guide. NC, USA: SAS Institute, Inc., Cary.

Solanelles, F., Planas, S., Escola, A., \& Rosell, J. R. (2002). Spray application efficiency of an electronic control system for proportional application to the canopy volume. Aspects of Applied Biology, 66, 139-146.

Solanelles, F., Escola, A., Planas, S., Rosell, J. R., Camp, F., \& Grácia, F. (2006). An electronic control system for pesticide application proportional to the canopy width of tree crops. Biosystems Engineering, 95, 473-481.

Sun, H., Slaughter, D. C., Pérez-Ruiz, M., Gliever, C., Upadhyaya, S. K., \& Smith, R. (2010). RTK GPS mapping of transplanted row crops. Computers and Electronics in Agriculture, 71(1), 32-37.

Udompetaikul, V., Shafii, M. S., Upadhayaya, S. K., Browne, G., \& Neves, D. (2008). Planting site-specific application of fumigant in orchards. Paper No. 083775. ASABE, St. Joseph, MI 49085, USA.

Van der Zande, D., Hoet, W., Jonckheere, I., Van Aardt, J., \& Coppin, P. (2006). Influence of measurement set-up of ground-based LIDAR for derivation of tree structure. Agricultural and Forest Meteorology, $141,147-160$.

Walklate, P. J., Cross, J. V., Richardson, G. M., Baker, D. E., \& Murray, R. A. (2003). A generic method of pesticide dose expression: application to broadcast spraying of apple trees. Annals of Applied Biology, $143,11-23$.

Ye, X., Sakai, K., Okamoto, H., \& Garciano, L. (2008). A ground-based hyperspectral imaging system for characterizing vegetation spectral features. Computers and Electronics in Agriculture, 63, 13-21. 